\title{
VR-Based Interactive Learning in Architectural Education: A Case on Safranbolu Historical Bathhouse
}

Eray Şahbaz*

\section{Abstract Purpose}

Historical buildings provide important information about the social life and architectural style of the era in which they were built. Perception of the effect of space by walkthrough is very important to perceive design philosophy of the structure for architecture students. However, for some reason, it may not be possible to see these structures in situ. VR technology has the potential to provide efficient solution to this problem. The study aims to provide an environment where students can learn architectural details and experience spatial effects of the historical buildings with the help of the VR technology as if they were in place.

\section{Design/Methodology/Approach}

In the scope of the study, an interactive VR program (IHVR) related with a historical Greek bathhouse has been developed and the effectiveness of it has been tested with a scientific experiment. A group of 45 volunteers from the architectural students were included in the study. The students were divided into three groups of 15 each called
Keywords: $\quad$ Virtual reality; simulation; interactive learning environments; architecture; hypermedia systems;

*Asst. Prof. Dr. Faculty of Architecture Kutahya Dumlupınar University, Turkey Email: eray.sahbaz@dpu.edu.tr ORCID No: https://orcid.org/00000002-5358-6100 
VR, field, and classroom. The students in the VR group experienced the IHVR program with virtual reality glasses while the students in the field group experienced the building on site and the classroom group students are told by the traditional method.

\section{Findings}

According to the test results, the students using the IHVR had a significant success compared to the other groups. It was observed that the interactive structure of the software helped the students to learn the historical building more effectively. As a result of the study, it was seen that IHVR was an efficient hypermedia tool in learning the architectural details and functions of the building.

\section{Practical Implications}

Experiencing historical structures in virtual environment as in real helps students to learn the architectural details more efficiently and experience spatial effects of the structure in a realistic way.

\section{Social Implications}

The widespread use of virtual reality will facilitate architectural education to keep up with technology and accelerate its adaptation to innovative approaches. The use of these technologies in architectural education will help to attract the interests of students to the subject that is intended to be explained more easily.

\section{Originality/Value}

The study leads to the development of VR-based hypermedia tools in applied architectural education.

\section{INTRODUCTION}

The rapid developments in technology along with the information age have deeply affected everyday life in all areas. Computers, which were an indispensable part of the business life even when the internet is not common, has begun to penetrate deeply into our social life as the internet becomes more popular. This situation has brought with it the increasing uncertainty of the boundaries between the virtual world and the real world. Virtual reality (VR) technology has taken this one step further and has made these boundaries more uncertain. This effect of virtual reality on human perception makes it an innovative tool candidate for architectural education as well as many other types of education. In the last 20 years various experimental projects have been developed on the use of VR technologies in architectural education.In1998 Virtual Environments Laboratory (VEL) was setup by the Research Unit of the Department of Architecture and Building Science of the University of Strathclyde (ABACUS). The facility had a curved-panoramic screen which sized $5 \times 2$ meters and received a high-resolution computer-generated image from three coordinated videoprojectors (Alvarado \& Maver, 1999). The VEL was suitable for architectural education because of holding several students inside it for collaborative learning. Another example of using virtual reality in architectural education is the VRAM (Virtual 
Reality Aided Modeler) project. VRAM is an immersive, threedimensional exploration and modeling tool (Regenbrecht et al, 2000). The project is designed to view, browse, edit, and create three dimensional models based on the Virtual Reality Modelling Language (VRML) (Donath \& Regenbrecht, 1999).

In the early 2000s, Maria Roussou developed a VR project to teach Hellenic culture and history to primary school children. In this project, Roussou used ImmersaDesk, a kind of touch screen, and standard stereo glasses to create a low-immersive virtual environment (Roussou, 2001). With the help of a 3D software, children can see ancient buildings in 3D and get information by touching them.

In the Mid-2000s Texas A\&M University Professor Mohammed E. Haque designed an application to present 3D visualization, animations, virtual reality, and walkthrough to demonstrate the construction process of various structures in Department of Construction Science (Brey, 2014; Haque, 2006). Around the same time, Jacobsen developed a VR game called Gate of Horus to lecture ancient Egyptian art and society using an educational learning game (Jacobson, 2008). The game is based on a simplified virtual model of an Egyptian temple.

Recently, Hyve-3D (Hybrid Virtual Environment 3D), an embodied collaborative sketching system that allows architectural design inside Virtual Reality by a new model of interaction through a 3D cursor was designed by Dorta, Kınayoğlu and Hoffman in Montreal University (Dorta et al, 2016). Project introduces a semi-spherical immersive 3D sketching environment based on spherical panoramas and uses 2D drawing planes that are intuitively manipulated in 3D space by the help of handheld tablets (Dorta et al, 2014).

\section{The Problem and Aim}

Therefore, historical buildings provide important information about the social life and architectural style of the era in which they were built, the preservation of historical buildings is as important as the designing of new structures in architectural education. It is important to preserve these buildings to ensure this information can be passed down to future generations firsthand. The preservation of historical buildings is also important insofar as it allows the spatial effect of the buildings to be experienced by walkthrough as opposed to simply reading about this effect in books or imagining it by looking at pictures. Taking a tour of the building offers the best opportunity to experience its architectural aura.

However, it may not be possible to experience a historical building in the field due to various circumstances. For instance, the building may no longer exist or too far away and therefore 
expensive to visit, or even if capable of being reached, entering it may be prohibited or dangerous because of dilapidation. In these cases, VR-based simulation applications have the potential to allow such structures to be experienced as if they were in place. This research seeks to answer the question of whether VR-based computer simulations powered with interactive tools can be used as an effective method for learning historical structures. It is thought that the above-mentioned problems can be overcome by experiencing the spatial effects of historical buildings in the most realistic way with the help of VR toolkits.

\section{INTERACTIVE HISTORICAL BUILDING VR (IHVR)}

In the study, a special software (IHVR) has been developed with the help of VR technology to solve the problems mentioned above and to set an example for lecturing the historical structures with VR and the effectiveness of this tool has been evaluated by a scientific experiment.

\section{Safranbolu Historical Bathhouse}

By the impression of the Roman Empire, the bathing was an important ritual for both Greek and Turkish nations in history. For this reason, in Anatolia that hosted these cultures, the architecture of bathhouses was highly advanced. Those buildings provide large amounts of important information about the architectural styles and cultures of their periods. Safranbolu is a World Heritage city in northern Turkey, and a 'crossroad city' of Turkish and Greek cultures. The building is located in the Krandaros (Kıranköy) district of Safranbolu where the Anatolian Greek (Rum) population mainly settled during the rule of the Ottoman Empire.

The building is in a convenient position on the terrain where the ancient Safranbolu houses are located. It is accessed from the upper elevation and it has four floors which vertically sweep towards the canyon (Figure 1). 
VR-Based Interactive Learning in Architectural Education: A Case on Safranbolu Historical Bathhouse

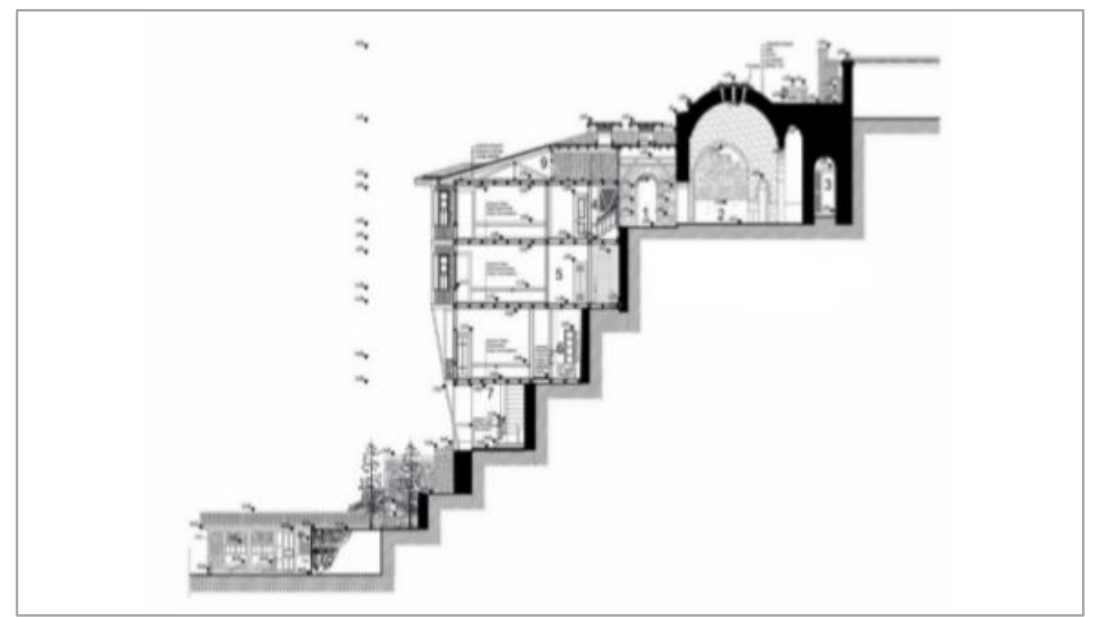

The building consisting of two main sections (Figure 2). One of these main sections is bath section, built in a Greek stone masonry style and where the bathing activity is made.

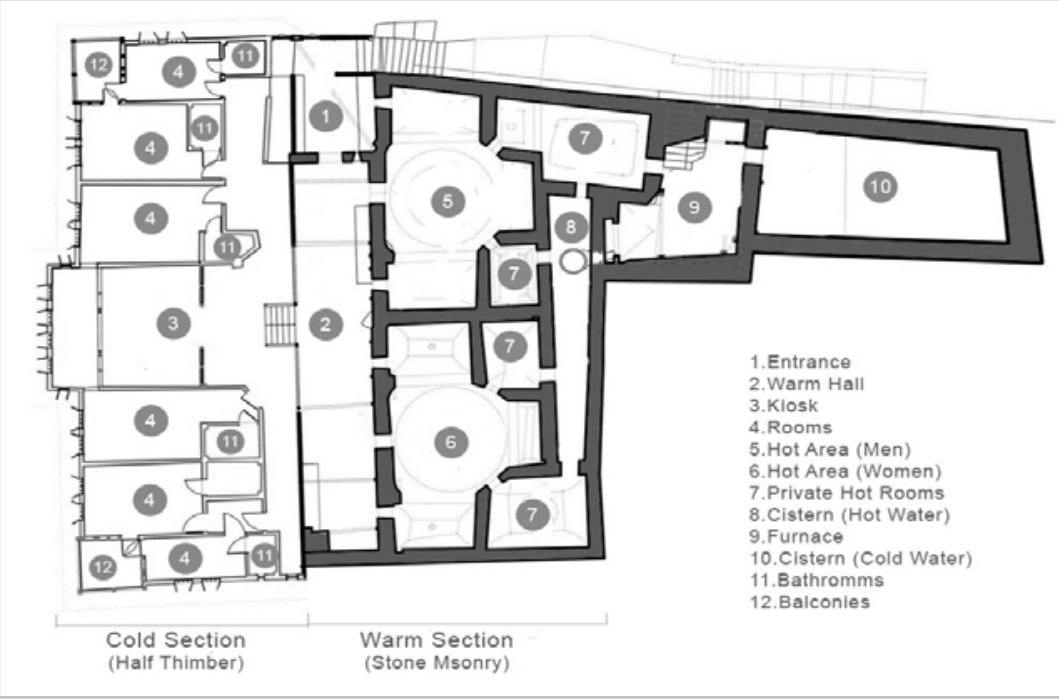

The other section (half-timber construction) is the 'cold area' (soyunmalık), in which users would prepare to bathe (Figure 3). Beside its architectural, cultural, social and iconic value, the bathhouse was chosen for its special rooms and architectural details.

Although the bathhouse had been all but ruined, a conservation process started in 2006 and it was completely restored. In this study, the projects approved by Conservation Council of Karabük were used to create a realistic measured 3D model of the bathhouse. The building was modeled in Blender using these technical drawings. The program supports the 3D modeling, rigging, animation, rendering, compositing, simulation and game creation.
Figure 1. Section of the Old Greek Bathhouse

Figure 2. Plan of the entrance floor 
Figure 3. The Front View of Safranbolu Historical Bathhouse

Figure 4. A Screen Capture from Development Process of IHVR

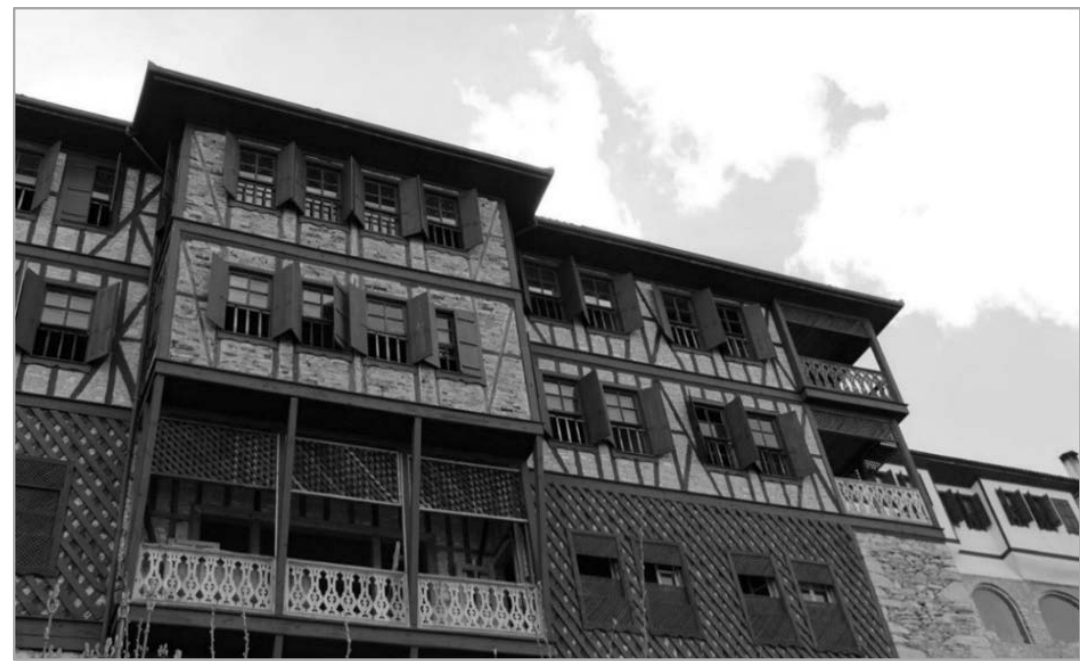

\section{Development of IHVR}

After the necessary arrangements were made, the historical Greek bathhouse, modeled in the Blender, was transferred to the Unreal Game Engine to develop VR platform of the IHVR (Figure 4). Unreal is a powerful game engine for professional computer games and supports VR tools such as Oculus Rift, HTC Vive and more. Oculus Rift head mounted display (HMD) and its touch controls were used for VR experience in this study. The product adjusts the created image by the lenses to cover the entire viewing angle of the user. Thus, the user is feeling surrounded by the virtual environment. It also detects the movements of the user through the motion sensors.

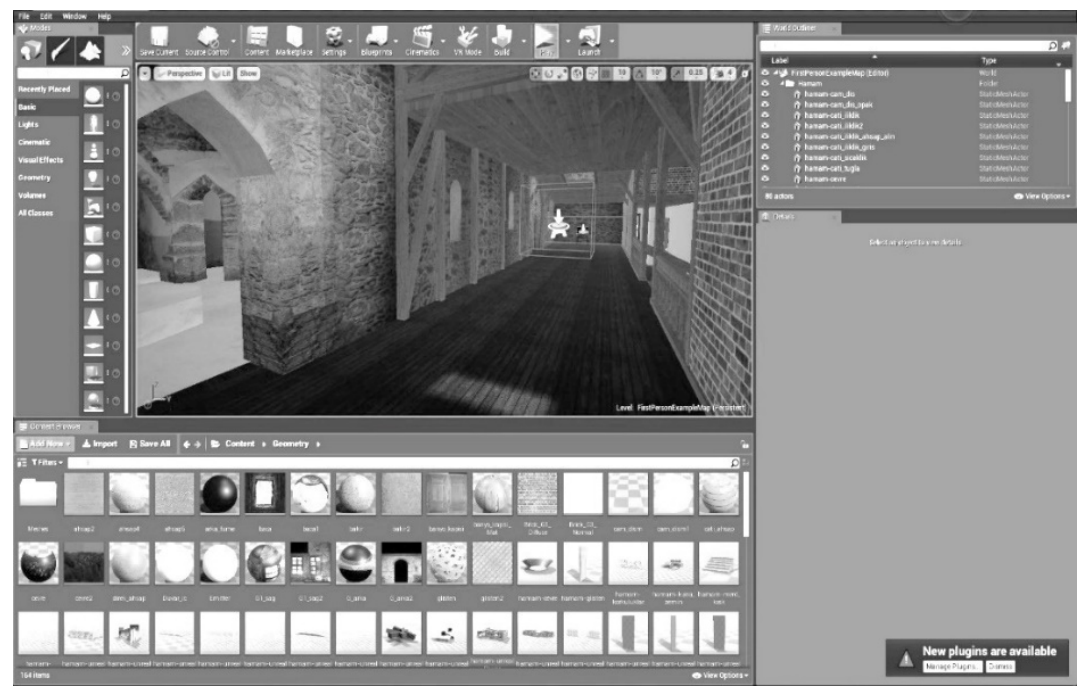

First-person shooter (FPS) games are very common among young people. For this reason, FPS interface, which is frequently used in computer games, is adopted as the user interface of the IHVR. In this interface a camera acts as eyes of the player and 
he/she sees the environment from his / her own eyes while moving the character.

\section{Interactive Tools of IHVR}

It is important to use interactive tools in learning process. Various interactive tools have been developed within the IHVR to enable students to interact with it and to encourage them to explore the building on their own by playing around with them. Students can interact with objects such as furnace, taps, walls, doors, ornaments, columns and beams within the program. With the help of these interactive tools, students have the opportunity to examine the spaces, layers, architectural elements and details that may not be possible to see in real life. For example, they can see the heat channels underneath the floor by hiding the its layer or they can switch on/off navel stone and basins which are not existing anymore in the current state of the bathhouse by touching the interactive switch button.

The most effective way of teaching something to someone is let him/her to do it (Schank et al, 1999). For this reason, one of the main objectives of interactive tools is to enable students to learn the functions of bathhouse not only by listening or seeing but also by doing.

In order to increase the students' desire to explore, some mysterious objects are scattered in various places. A student can use any of these objects if he / she discovers what it is used for by using his / her own knowledge gained from the architectural education. For example, when students find the matchbox laying on the ground, they can use it to light the heater in the furnace room. So, they can practically experience the functions of the furnace room (how the furnace burns, and smoke is evacuated).

The aim is to eliminate the limitations of the classroom environment with VR technology and to enable students to learn by experiencing the functions of the structure. Within the scope of the study, it was also evaluated the effect of these tools and activities on students' success rates.

\section{IHVR VS TRADITIONAL METHODS}

The experiment aimed to compare the success rates of the three methods applied separately on the three groups. The first method was the VR-based method supported by the IHVR. The second method was a traditional experiment method (visiting the building in the field). Lastly, the third method was the traditional teaching method, which was administered in the classroom.

The participants were randomlyselected from the Architecture Department of a university in Turkey. In total, 45 volunteer undergraduate students who had never attended a 
lecture on the building in question before took part in the experiment. The volunteers were gathered in a classroom and informed about the research. The participants were then separated into three groups of equal size, with the separate groups being designated as "VR", "field" and "classroom". A pre-experiment test was administered to all groups to measure their current knowledge about the building in question. Every question had a value of 10 points, and the maximum value of points a student could gain was 100 .

The mean scores obtained by the VR group, field group and classroom group were 10.67 ( $S D=10.50), 11.33$ ( $\mathrm{SD}=15.06)$ and $12.00(\mathrm{SD}=8.41)$, respectively. The test of homogeneity of variances showed that all groups were separated homogeneously $(p=0.208)$. According to the Tukey honest significant difference test, it was confirmed that the difference between the groups was insignificant $(p=0.987, p=0.947)$, as shown in Table 1.

Table 1. Multiple Comparisons Results of Pre-Experiment Test

\begin{tabular}{lllllll}
\hline (I) Group & (J) Group & (I - J) & Std. Error & $\mathbf{P}^{*}$ & $\begin{array}{l}\text { Lower Upper } \\
\text { Bound Bound }\end{array}$ \\
\hline Field & Classroom & -.67 & 4.26 & .987 & -11.019 .67 \\
& VR & .67 & 4.26 & .987 & -9.67 & 11.01 \\
\hline \multicolumn{2}{l}{ Classroom Field } & .67 & 4.26 & .987 & -9.67 & 11.01 \\
& VR & 1.33 & 4.26 & .947 & -9.01 & 11.67 \\
\hline VR & Field & -.67 & 4.26 & .987 & -11.019 .67 \\
& Classroom & -1.33 & 4.26 & .947 & -11.679 .01
\end{tabular}

${ }^{*} \mathrm{p}$ value must be less than 0.05 for significant difference between groups

\section{The Experiment Process}

The aim of the experiment is to measure the effectiveness of IHVR against traditional methods used in teaching historical structures. For this purpose, IHVR has been compared with traditional methods such as lecturing the building in classroom and on site. In the first step of the experiment, a lecture on an historical bathhouse was presented in the classroom using traditional course materials, such as books, lecturing notes and slide shows. Architectural and technical details of the building were explained by comparing them to details from other buildings, and the different periods that the building had gone through were discussed in detail. The field group visited the Historical Greek Bathhouse as part of the traditional visit method. The lecturer explained and pointed out, on-site, each of the architectural details of the historic bathhouse, room by room, to the participants, as is done in traditional field lessons. 
The VR group met together in a computer laboratory and was briefly trained in how to use Oculus Rift VR toolkit (Figure 5). After undergoing basic training, the students experienced the building through IHVR.

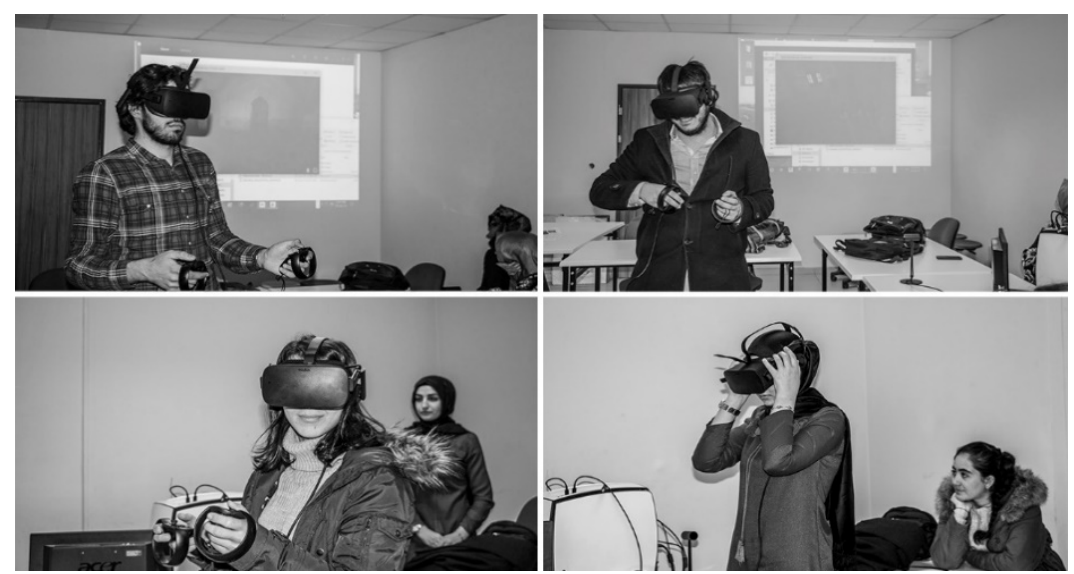

Figure 5. VR Group in training

A final post-experiment test of 15 questions was administered to compare the mean scores of the groups. The questions were categorized under three main categories to measure the success rates of the VR-based method in different architectural areas. These categories were architectural details, building construction and building design.

There were six architectural details category questions on the test, which were chosen on the basis of the cultural values and unique architectural details present in the building, such as the ornamentations, reliefs, wall paintings, skylights and stained-glassed windows. There were five building construction category questions selected on the technical details of the building, such as the materials, construction types, stairs, installations and roofs. Lastly, there were four building design questions, chosen from spaces, rooms and their functions in the building.

\section{Test Results}

Figure 6 shows the comparison of the mean success rates between the VR group, the field group and the classroom group. The results show that the post-test scores of all groups were higher than their pretest scores. 
Figure 6. Comparison of the PreTest and Post-Test Scores of the Groups

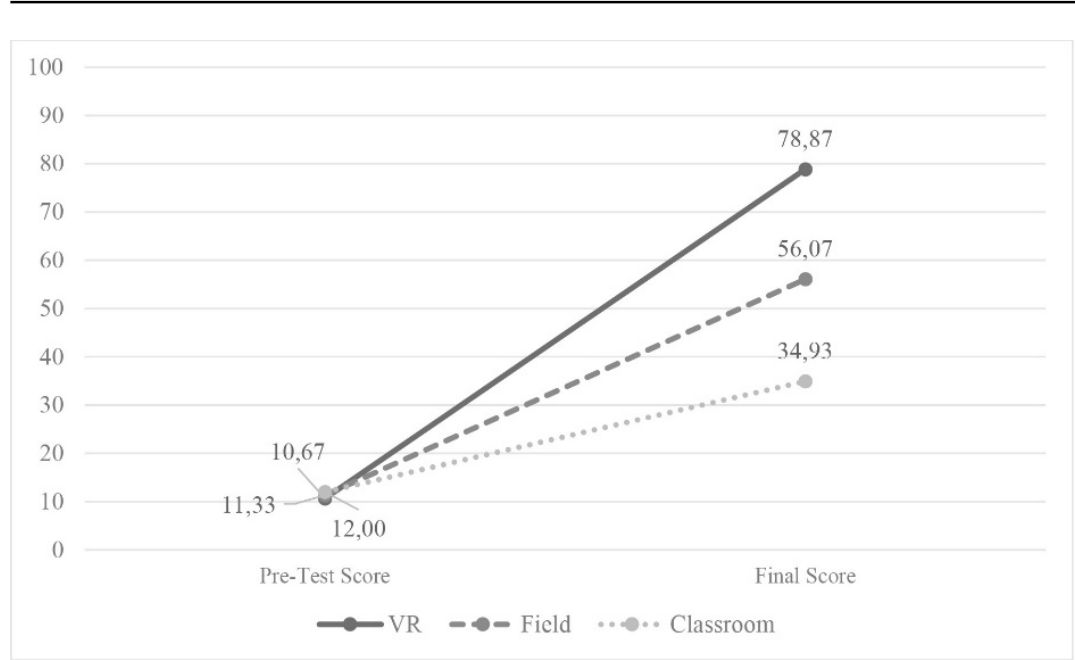

A multiple comparison (Tukey honest significant difference) test was conducted to compare the mean scores of the groups. The posttest scores of the VR group $(M=78.87, S D=19.12)$ were higher than those of the field group $(M=56.07, S D=11.68)$ and the classroom group $(\mathrm{M}=34.93, \mathrm{SD}=15.34)$, as shown in Table 2 . According to the test results, the difference between the VR group and the field group was significant $(p=0.007)$. The difference between the VR group and the classroom group was also significant $(\mathrm{p}=0.000)$.

These results confirm that the IHVR really does have an effect on experiencing the historical building. Specifically, the results suggest that when students played VR-based simulation, they obtained more knowledge about the building.

Table 2. Multiple Comparisons Test Results of Final Scores

\begin{tabular}{|c|c|c|c|c|c|c|}
\hline (I) Group & (J) Group & $(\mathrm{I}-\mathrm{J})$ & Std. Error & $\mathbf{P}^{*}$ & $\begin{array}{l}\text { Lower } \\
\text { Bound }\end{array}$ & $\begin{array}{l}\text { Upper } \\
\text { Bound }\end{array}$ \\
\hline \multirow[t]{2}{*}{ VR } & Field & 22.80 & 5.72 & .001 & 8.89 & 36.71 \\
\hline & Classroom & 43.93 & 5.72 & .000 & 30.03 & 57.84 \\
\hline \multirow[t]{2}{*}{ Field } & VR & -22.80 & 5.72 & .001 & -36.71 & -8.89 \\
\hline & Classroom & 21.13 & 5.72 & .002 & 7.23 & 35.04 \\
\hline \multirow[t]{2}{*}{ Classroom } & VR & -43.93 & 5.72 & .000 & -57.84 & -30.03 \\
\hline & Field & -21.13 & 5.72 & .002 & -35.04 & -7.23 \\
\hline
\end{tabular}

*p value must be less than 0.05 for significant difference between groups

Table 3 shows the comparison of the mean scores between the three groups in terms of the architectural details category questions. The mean score of the VR group ( $M=34.40, S D=9.57)$ was significantly higher than that of the field group $(M=22.93$, $\mathrm{SD}=10.63, \mathrm{p}=0.005)$ and that of the classroom group $(\mathrm{M}=15.60$, $\mathrm{SD}=7.68, \mathrm{p}=0.000$ ). The mean difference between the classroom 
VR-Based Interactive Learning in Architectural Education: A Case on Safranbolu Historical Bathhouse

group and the field group was determined to be insignificant ( $\mathrm{p}=0.093$ ).

This, therefore, indicates that the students who had used IHVR obtained more knowledge about the architectural details category than others. It seems that the IHVR provided the projected success in this category.

Table 3. Multiple Comparisons Test Results on Architectural Details Category

\begin{tabular}{|c|c|c|c|c|c|c|}
\hline (I) Group & (J) Group & $(I-J)$ & $\begin{array}{l}\text { Std. } \\
\text { Error }\end{array}$ & $\mathbf{P}^{*}$ & $\begin{array}{l}\text { Lower } \\
\text { Bound }\end{array}$ & $\begin{array}{l}\text { Upper } \\
\text { Bound }\end{array}$ \\
\hline \multirow[t]{2}{*}{ VR } & Field & 11.47 & 3.42 & .005 & 3.15 & 19.78 \\
\hline & Classroom & 18.80 & 3.42 & .000 & 10.48 & 27.12 \\
\hline \multirow[t]{2}{*}{ Field } & VR & -11.47 & 3.42 & .005 & $5-19.78$ & -3.15 \\
\hline & Classroom & 7.33 & 3.42 & .093 & $3-.98$ & 15.65 \\
\hline \multicolumn{2}{|c|}{ Classroom VR } & -18.80 & 3.42 & .000 & -27.12 & -10.48 \\
\hline & Field & -7.33 & 3.42 & .093 & $3-15.65$ & .98 \\
\hline
\end{tabular}

*p value must be less than 0.05 for significant difference between groups

The VR group had higher mean scores ( $M=20.07, S D=8.02)$ than those obtained by the field group ( $M=16.40, \mathrm{SD}=5.62)$ and the classroom group $(M=10.00, S D=7.99)$ in the construction building category (Table 4). The difference between the field group and the classroom group $(\mathrm{p}=0.053)$ and the difference between the field group and the VR group ( $\mathrm{p}=0.362)$ was insignificant. However, according to the test results, the difference between the VR group and the classroom group was significant $(\mathrm{p}=0.001)$.

Table 4. Multiple Comparisons Test Results on Building Construction Category

\begin{tabular}{lllllll}
\hline (I) Group & (J) Group & (I - J) & \multicolumn{2}{l}{ Std. Error } & $\mathbf{P}^{*}$ & \multicolumn{2}{l}{$\begin{array}{l}\text { Lower } \\
\text { Bound }\end{array}$} & Bound \\
\hline VR & Field & 3.67 & 2.66 & .362 & -2.81 & 10.14 \\
& Classroom & 10.07 & 2.66 & .001 & 3.59 & 16.54 \\
\hline Field & VR & -3.67 & 2.66 & .362 & -10.14 & 2.81 \\
& Classroom & 6.40 & 2.66 & .053 & -.07 & 12.87 \\
\hline Classroom & VR & -10.07 & 2.66 & .001 & -16.54 & -3.59 \\
& Field & -6.40 & 2.66 & .053 & -12.87 & .07
\end{tabular}

${ }^{*} \mathrm{p}$ value must be less than 0.05 for significant difference between groups

Although the VR group became more successful than the classroom group in this category, the projected success rate was not provided. The results show that the VR group students obtained more knowledge about the building construction category than both of the VR and classroom group. It is 
recognized that the VR group did not gain significant knowledge about this category. These results also confirm that the IHVR needs more development in building construction category.

In the building design category, the mean score of the VR group $(M=24.27, S D=8.03)$ was significantly higher than that of the field group ( $M=16.80, S D=5.39, p=0.013)$ and that of the classroom group ( $M=9.33, S D=6.96, p=0.000)$, as shown in Table 5 . The difference between the mean scores of the field group and the classroom group was significant $(p=0.013)$.

This, therefore, indicates that the VR group obtained more knowledge about the building design category than other groups. The VR provided the projected success in teaching design principles of the historical building.

Table 5. Multiple Comparison Test Results on Building Design Category

\begin{tabular}{|c|c|c|c|c|c|c|}
\hline (I) Group & (J) Group & $(\mathrm{I}-\mathrm{J})$ & Std. Error & $\mathbf{P}^{*}$ & $\begin{array}{l}\text { Lower } \\
\text { Bound }\end{array}$ & $\begin{array}{l}\text { Upper } \\
\text { Bound }\end{array}$ \\
\hline \multirow[t]{2}{*}{ VR } & Field & 7.47 & 2.51 & .013 & 1.37 & 13.57 \\
\hline & Classroom & 14.93 & 2.51 & .000 & 8.83 & 21.03 \\
\hline \multirow[t]{2}{*}{ Field } & VR & -7.47 & 2.51 & .013 & -13.57 & -1.37 \\
\hline & Classroom & 7.47 & 2.51 & .013 & 1.37 & 13.57 \\
\hline \multirow[t]{2}{*}{ Classroom } & VR & -14.93 & 2.51 & .000 & -21.03 & -8.83 \\
\hline & Field & -7.47 & 2.51 & .013 & -13.57 & -1.37 \\
\hline
\end{tabular}

${ }^{*} \mathrm{p}$ value must be less than 0.05 for significant difference between groups

\section{DISCUSSION AND CONCLUSION}

In this study, it is examined whether VR technology can solve the problems encountered during the learning process of historical buildings. With VR technology, it is thought that the spatial effects of historical buildings will be experienced in a realistic way and even with interactive tools this experience can be taken one step further. To gain new knowledge, the students could interact VR objects (Roussos et al., 1999), do or make something, alone or in a collaborative group work (Jacobson, 2008). This hypothesis was tested by IHVR in Safranbolu Historical Greek Bath. Both test results and user feedbacks justified this hypothesis.

The experiment revealed that providing students with the opportunity to play with and be entertained by interactive hypermedia tools enriches and broadens both the scope of activity and scope of thinking. According to test results, the IHVR had a significant success rate in terms of how well the students learned about historical buildings and was also found to be more effective than traditional lecturing methods. The interactive user interface of the program had an important role in this success. 
The game-like structure of the program, which had the dual advantage of being able to lecture the students as well as entertain them, helped them to explore the building in a highly efficient manner.

IHVR helped students experience the structure in the most realistic way without seeing it in the field. With interactive features of IHVR the students could improve their observation, discovery and focusing abilities. IHVR provides students the opportunity to learn by doing and facilitates an enjoyable learning experience and aim to encourage students to explore, try and understand by playing an active role in the learning process (Jonassen, 1996). However, it should be remembered that VR features alone do not determine the whole learning process, all other factors, such as concepts or skills to be learned, individual characteristics, learning experience and interaction experience, all play a role in shaping the learning process and its outcomes (Salzman et al, 1999).

The test results show that VR-based computer programs are efficient hypermedia tools for giving students the opportunity to experience-based learning about historical buildings. The activities which students have chance to see the old and current condition of the spaces, get visual and audio information about the places and learn the activities by applying the functions of the structure, helped them to explore the building. Using these tools to support traditional learning methods can serve to enrich the content of the class (Kraten, 2015). These tools are efficient in drawing the attention of students to the subject at hand. The students were excited and motivated by the fact that they had the opportunity to have fun and explore the building, just as if they were playing a computer game.

The usage area of the VR tools in architectural education is not limited with the experiencing historical buildings. They have also a great potential to help architectural students improve their professional skills by distance (online) and cooperative training. Students could learn many things about their professions by collaborating and taking responsibilities as in online multiplayer games.

These technologies can be used as a modern, effective method in teaching both old and new production techniques in an applied way. 3D computer simulations help practically to teach construction techniques with the help of virtual reality technology. Also, in the lecturing of restoration techniques, these technologies have great potentials. Students can learn the special techniques of restoration with head mounted displays, as if they are inside the structure. In the preparation of the students for professional life, the architectural processes such as the operation of a construction site, the completion of a building 
from design to construction can be easily imitated by VR tools, as is done in IHVR.

\section{REFERENCES}

Alvarado, R. G., \& Maver, T. W. (1999). Virtual Reality in Architectural Education: Defining Possibilities. ACADIA Quarterly, 18.

Brey, P. (2014). Virtual Reality and Computer Simulation BT Ethics and Emerging Technologies. In R. L. Sandler (Ed.), Ethics and Emerging Technologies, 315-332. London: Palgrave Macmillan UK.

Donath, D., \& Regenbrecht, H. (1999). Using Immersive Virtual Reality Systems for Spatial Design in Architecture. AVOCAAD'99 Conference, 307-318.

Dorta, T, Kinayoglu, G., \& Hoffmann, M. (2014). Hyve-3D: A New Embodied Interface for Immersive Collaborative $3 D$ Sketching. https://doi.org/10.1145/2619195.2656325

Dorta, T, Kinayoglu, G., \& Hoffmann, M. (2016). Hyve-3D and the 3D Cursor: Architectural co-design with freedom in Virtual Reality. International Journal of Architectural Computing, 14(2), 87-102.

Haque, M. E. (2006). Virtual Reality and Learner-Centered Pedagogy: Technology's New Role For The Architectural Engineering Students. In J. Al-Qawasmi, G. P. Vasquez de Velasco, \& C. for the S. of A. in the A. Region. (Eds.), Changing trends in architectural design education, 205-215, Morocco: CSAAR.

Jacobson, J. (2008). Ancient Architecture in Virtual Reality; Does Visual Immersion Really Aid Learning? Retrieved from http://d-scholarship.pitt.edu/7499/

Jonassen, D. H. (1996). Computers in the classroom: mindtools for critical thinking. In $N$ J Prentice Hall. New Jersey: Merril.

Kraten, M. (2015). Social Presence Theory And Experiential Learning Games. Business Education Innovation Journal, $7(2), 6-16$.

Regenbrecht, H., Kruijff, E., Donath, D., Seichter, H., \& Beetz, J. (2000). VRAM - a Virtual Reality Aided Modeler.

Roussos, M., Johnson, A., Moher, T., Leigh, J., Vasilakis, C., \& Barnes, C. (1999). Learning and Building Together in an Immersive Virtual World. Presence: Teleoper. Virtual Environ., 8(3), 247-263.

Roussou, M. (2001). Immersive Interactive Virtual Reality and Informal Education. Proceedings of User Interfaces for All: Interactive Learning Environments for Children, 1-9. Athens.

Salzman, M. C., Dede, C., Loftin, R. B., \& Chen, J. (1999). A Model for Understanding How Virtual Reality Aids Complex Conceptual Learning. Presence: Teleoper. Virtual Environ., 8(3), 293-316. https://doi.org/10.1162/10547469956624 2

Schank, R. C., Berman, T. R., \& Macpherson, K. A. (1999). Learning By Doing. In C. M. Reigeluth (Ed.), Instructional-design Theories and Models: A New Paradigm of Instructional Theory, 161-183. New Jersey: Routledge. 
VR-Based Interactive Learning in Architectural Education: A Case on Safranbolu Historical Bathhouse

\section{Resume}

Eray ŞAHBAZ is Assistant Professor Dr. at Faculty of Architecture at Kutahya Dumlupınar University, Turkey. He received his bachelor's degree from the Erciyes University and MSc from the Eskişehir Osmangazi University. He completed his PhD in Karabuk University. Dr. Şahbaz's research interests include using computer games, simulations, virtual reality, and augmented reality in architectural education. 